\title{
SAGE GROUSE CHICK SURVIVAL RATES IN JACKSON HOLE
}

\author{
BRYAN BEDROSIN $\uparrow$ ROSS CRANDALL \\ CRAIGHEAD BERINGIA SOUTH $\uparrow$ KELLY WY
}

\section{$\downarrow \quad$ INTRODUCTION}

The Greater Sage-grouse (Centrocerus urophasianus) population within Jackson Hole has been declining over the past 60 years (Holloran and Anderson 2004). Currently, several unknown population parameters may affect population models, such as nesting productivity (and annual variation therein), nest initiation and re-nesting rates, sex ratio of chicks produced, chick survival, and annual subadult and adult survival rates. While previous research has investigated some of these demographic parameters for the Jackson Hole sage-grouse population (Holloran and Anderson 2004); those estimates may not be adequate due to sample size limitations. Further, there are new constraints on this population due to drastic changes in the wintering habitat from wildfires since those estimates were obtained.

Different demographic parameters have been suggested as the limiting factors for the grouse population in Jackson Hole. Holloran and Anderson (2004) proposed that an increase in female survival and a large increase in fertility (production) would result in an increase in overall population size. However, using estimates from Holloran and Anderson (2004), McDonald (2006) developed a stochastic model that suggested adult survival was the limiting factor for the Jackson Region, not productivity. Both studies used estimate parameters from other populations within their models and suggested better estimates of survival and productivity were needed to refine those models due to sample size constraints for data collected by Holloran and Anderson (2004).
We have been able to collect data to obtain estimates of sub-adult and adult survival rates, nesting success, re-nesting rates, and productivity for the population of sage-grouse in Jackson Hole. However, to obtain accurate population growth models and to identify limiting factors of the Jackson Hole grouse population, it is imperative to have accurate estimates of all demographic information of the population in question (McDonald 2006). As such, we initiated a project to investigate the chick survival rates in Jackson Hole to complete the sagegrouse demographic estimates needed.

\section{$\uparrow \quad$ METHODS}

We used our sample of previously radiomarked females to locate nests during the spring and early summer of 2009 . Females were monitored every 2-3 days to determine if they localized at a nest site. Once localization occurred, we approached the nesting female to within $30 \mathrm{~m}$ and circled the nest location. We then monitored nesting females every 2-3 d from $>100 \mathrm{~m}$ to determine when she left the nest site. After the hen left, we returned to the site to find the nest and determine the outcome of the attempt by examining egg shell remains (Connelly et al. 2003). If the nesting attempt was successful, we located broods by radio tracking the brood hen from 2-6 days after hatching. Sage-grouse chicks were caught by hand and $1.5 \mathrm{~g}$ radio transmitters (Advanced Telemetry Systems, Insanti, MN; $<4 \%$ of chick body mass at time of capture) were placed on all chicks captured (Figure 1). Prior to attempting captures on chicks, we de-scented our clothing and 
wore rubber boots and gloves as a precaution against later predator detection of the chicks due to handling (Connelly et al. 2003). Transmitters were attached to chicks using the suture method described in Burkepile et al. (2002), as other methods of attachment, such as backpack transmitters and implants have proven to be unsuitable for fastgrowing, precocial species (Hubbard et al. 1996). All chicks were released simultaneously to ease hens gathering broods after handling (Burkepile et al. 2002).

Once outfitted, we re-located hens every 2 days and determined if the outfitted chicks were within $40 \mathrm{~m}$ of the hens and therefore assumed to be alive. If chicks were not located near the hen, we exhaustively searched for the chick and examined the surrounding area for transmitters/remains as evidence of predators to determine cause of death (Hennefer 2007).

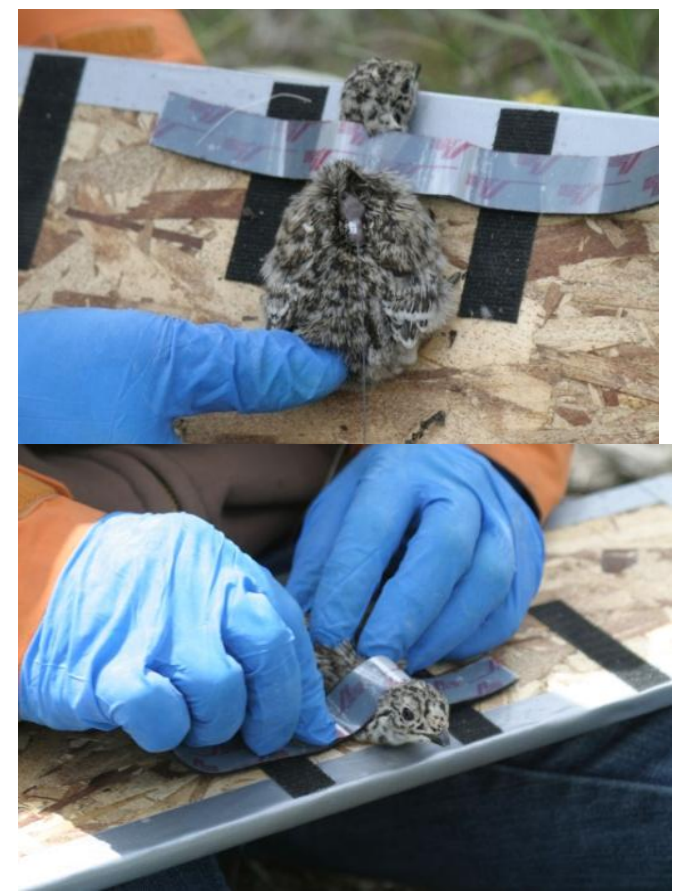

Figure 1. Outfitting chicks with transmitters.

\section{$\uparrow \quad$ RESULTS}

We attempted to outfit sage-grouse chicks from the first broods found in 2009. The first capture attempt was on 11 June, five days following a successful nesting attempt by a hen with nine chicks hatched. Upon flushing, the hen acted with typical defense behavior and flushed $>20 \mathrm{~m}$ away. We immediately began searching the area for chicks and only found one hiding below thick antelope bitterbrush (Purshia tridentate). We placed this chick in a holding bag while we exhaustively searched the area for more chicks without success. We outfitted the chick with a transmitter, took a feather sample and released the chick within $15 \mathrm{~min}$ after capture. On 12 June, we attempted to locate the chicks from another hen that hatched six young two days prior. Upon flushing the hen, we were able to locate a total of three chicks and all were outfitted with transmitters. On 22 June, we were only able to locate and capture two chicks from a brood of nine, two days post-hatch. Both were fitted with transmitters.

We followed the first chick for a total of 59 days post-hatch and concluded this chick successfully fledged. Of the three chicks in the second brood captured, we found one chick transmitter 4 days after attachment. There was no sign of the chick or predation so the fate of the chick could not be determined. On the same check date, the other two transmitters from that brood were not with the hen nor could be located. We subsequently flushed the hen who exhibited no signs of having chicks (e.g., defensive behavior, flushing very short distances). We determined this hen had lost her entire brood. We were unable to locate the transmitters on a subsequent telemetry flight. One of the two chicks from the final brood was found intact with the transmitter still attached two days post-capture. Upon examination, we found a blockage in the digestive tract but could not accurately determine cause of death. The other chick's transmitter was found on the same day with no trace of the body or evidence to suggest death or attachment failure.

\section{$\uparrow \quad$ DISCUSSION}

Our original study plan to document chick mortality and causes of death included outfitting all chicks from every brood monitored during the 2009 field season ( $\mathrm{n}=68$ chicks from 10 nests). We quickly realized that we could not locate all the chicks from a brood, as has been done in similar studies (e.g., Burkpile et al. 2002, Gregg et al. 2007). Based on that capture rate and the lack of information gathered from mortalities, we decided the disturbance to our study animals did not outweigh the cost of gathering these few data. We subsequently abandoned the remainder of the study.

A flush count at 30 days post-hatch indicated the outfitted chick from the first brood was one of four that survived the late brood-rearing period. From the second brood outfitted with 
transmitters, we concluded that a predation event likely occurred that caused the death of all chicks in the brood. This is also supported by the fact we could not locate two of the three transmitters which may be indicative of a predation event (Gregg et al. 2007). An early brood count from the final brood indicated that at least two chicks from that clutch survived to 15 days post-hatch.

Based on early (15 days post-hatch) and late (30 days post-hatch) flush counts, we estimate an $87 \%$ mortality rate during the early brood rearing phase and of those who survive a 33\% mortality rate from the early to late brood-rearing period. Overall, there was a $92 \%$ chick mortality rate based on brood counts. This estimate is much higher than studies in other areas based on telemetry data (Burkpile et al. 2002 74\%, Gregg et al. 2007 78\%, Hennefer 2007 $78 \%$ ). We, however, do not know the extent of brood swapping or un-flushed chicks which may over estimate our chick survival estimates based on brood counts.

Hennefer (2007) also attempted to use micro-transmitters on sage grouse chicks to estimate survival and causes of mortality but found similar issues to this study. In Gregg et al. (2007), the researchers assumed that lost transmitters were a result of predation and that transmitters found by themselves with no evidence of the chick were not a result of predation. These assumptions have obvious implications for overall survival rates and may not accurately reflect the truth of what happened. Similar to our study, Hennefer (2007) found no unsuspected causes of death and concluded that the cost of increased stress to the study animals did not outweigh the knowledge gained from the study, especially in small and recovering populations. Jackson Hole however is host to ca. 400 individuals and the sample size of chicks needed to adequately address the objectives of this study is unrealistic due to the capture difficulties encountered.

It is our suggestion that in small populations of sage grouse, such as Jackson Hole, that radio transmitters to assess mortality for chicks should not be used. Based on our limited observations, it appears that gathering valid data on causes of mortality is unlikely. Further, finding transmitters by themselves lends to assumptions about chick survival that may not be accurate. Coupled with the problems we encountered catching full broods, we feel that the discontinuation of this study was warranted and estimates of productivity are better assessed using a combination of brood counts and adult/juvenile ratios during lek counts.

\section{ACKNOWLEGEMENTS}

Derek Craighead provided invaluable insights and support for this project. Howard Quigley, Sue Wolff, Joe Bohne, and Steve Cain provided logistical support. Megan Reuhmann and Trapper Haynam were extremely helpful in the field. This project was funded, in part, by the Wyoming Game and Fish Department, the Upper Snake River Basin Working Group, the Jackson Hole Airport, Grand Teton National Park, the University of Wyoming, and a variety of private donors.

\section{$\uparrow \quad$ Literature Cited}

Burkepile NA, Connelly JW, Stanely DW, Reese, KP. 2002. Attachment of radiotransmitters to one-day-old sage grouse chicks. Wildlife Society Bulletin 30:93-96.

Connelly JW, Reese KP, Schroeder MA. 2003. Monitoring of Greater Sage-grouse habitats and populations. Moscow (ID): College of Natural Resources Experimental Station. Station Bulletin 80.

Gregg MA, Dunbar MR, Crawford JA. 2007. Use of implanted transmitters to estimate the survival of Greater Sage-grouse chicks. Journal of Wildlife Management 71:646651.

Hennefer JP. 2007. Analysis of Greater Sage-grouse (Centrocercus urophasianus) translocation release methods and chick survival in Strawberry Valley, Utah [Thesis]. Provo (UT): Brigham Young University.

Holloran MJ, Anderson SH. 2004. Greater Sagegrouse seasonal habitat selection and survival in Jackson Hole, Wyoming. Completion Report. Laramie (WY): Wyoming Cooperative Fish and Wildlife Unit, University of Wyoming.

Hubbard MW, Tsao LC, Klass EE, Kaiser M, Jackson DH. 1998. Evaluation of transmitter attachment techniques on growth rates of wild turkey poults. Journal of Wildlife Management 62:547-1578. 
Korschgen CE, Kenow KP, Green WL, Johnson DH, Samuel MD, Sileo L. 1996. Technique for implanting radio transmitters subcutaneously in day-old ducklings. Journal of Field Ornithology 67:392-397.
McDonald DB. 2006. Demographic population assessment of Greater Sage-grouse in Jackson Hole, WY. Completion Report. Laramie (WY): University of Wyoming. 